Chapman University

Chapman University Digital Commons

English (MA) Theses

Dissertations and Theses

Spring 5-2021

\title{
Collaborative Storytelling: Composition Pedagogy and Communal Benefits of Narrative Innovation
}

\author{
Aysel Atamdede \\ Chapman University, atamd100@mail.chapman.edu
}

Follow this and additional works at: https://digitalcommons.chapman.edu/english_theses

Part of the Other English Language and Literature Commons

\section{Recommended Citation \\ Atamdede, Aysel. Collaborative Storytelling: Composition Pedagogy and Communal Benefits of Narrative Innovation. 2021. Chapman University, MA Thesis. Chapman University Digital Commons, https://doi.org/ $10.36837 /$ chapman.000257}

This Thesis is brought to you for free and open access by the Dissertations and Theses at Chapman University Digital Commons. It has been accepted for inclusion in English (MA) Theses by an authorized administrator of Chapman University Digital Commons. For more information, please contact laughtin@chapman.edu. 


\title{
Collaborative Storytelling: Composition Pedagogy and Communal Benefits of Narrative Innovation
}

\author{
A Thesis by \\ Aysel Atamdede \\ Chapman University \\ Orange, $\mathrm{CA}$ \\ Wilkinson College of Arts, Humanities, and Social Sciences \\ Submitted in partial fulfillment of the requirements for the degree of \\ Master of Arts in English
}

May 2021

Committee in charge:

Ian Barnard, Ph.D., Chair

Morgan Read-Davidson, MFA

Jan Osborn, Ph.D. 
The thesis of Aysel Atamdede is approved.

Aan Barnard

Ian Barnard, Ph.D., Chair

Morgan Read-Davidson

Morgan Read-Davidson, MFA

$\frac{\text { Qan M. Osborn }}{\text { Jan Osborn, Ph.D. }}$

May 2021 
Collaborative Storytelling: Composition Pedagogy and Communal

\section{Benefits of Narrative Innovation}

Copyright (C) 2021

by Aysel Atamdede 


\section{ACKNOWLEDGEMENTS}

First and foremost, I would love to thank my committee for their enthusiasm and feedback throughout the writing process. To my advisor, Ian Barnard, the biggest of thanks for your encouragement and guidance as I worked through the drafting and editing process. It's been a long and arduous process, but I couldn't have done it without your help. To Morgan ReadDavidson, my first committee member, my endless gratitude for your feedback and enthusiasm for my topic, and the wealth of recommendations for readings and reference material you provided. To Jan Osborn, my second committee member, thank you for your interest in my topic and feedback throughout the drafting process. To Chapman University and the Wilkinson College English Department, my gratitude for allowing the opportunity for me to explore my interests and to write this thesis as a result of my passion.

I'd like to thank my friends for providing me with the initial exposure to the tabletop gaming community, and the ongoing campaigns that I've been a part of. It's been a journey unlike anything else, and without you I might never have thought to explore the application of gaming practices in pedagogy, or the potential innovation of RPG narrative structure in the composition courses.

To my family, thank you for being with me as I pursued the next step in my education. This program has been a boon for me creatively and academically, and this opportunity was truly once in a lifetime. Even if you don't understand my fascination with hoarding dice or spending hours on end playing make-believe with my friends, your enthusiasm and support for my pursuits is something I can't thank you enough for. 


\begin{abstract}
\end{abstract}
Collaborative Storytelling: Composition Pedagogy and Communal Benefits of Narrative Innovation

by Aysel Atamdede

Can gaming be considered narrative? Should gaming be allowed in a pedagogical space? Tabletop roleplaying games are probably not the first thing that come to mind when thinking about how to innovate narrative structure and teaching composition. Often considered a nerdy pastime, participants ridiculed for playing pretend and caring about imaginary characters, TTRPGs have nonetheless entered a sort of renaissance in recent years. While video games have slowly become more incorporated into pedagogy by teaching students more abstract concepts of interactivity with narrative, audience, and player engagement, TTRPGs have been slower on the draw. But incorporating the highly interactive and freeform narrative structure into composition curriculum is far from impossible. In addition to helping students break out of their comfort zones, TTRPG-like assignments can help build community and strengthen communication skills, allow students to explore ownership and leadership in group work, and teach real-time improvisation and problem-solving techniques. TTRPGs are a vastly underestimated and underutilized form of narrative structure and innovation, and deserve consideration as a valid form of composition and pedagogy for practical and theoretical applications. 


\section{TABLE OF CONTENTS}

$\underline{\text { Page }}$

ACKNOWLEDGEMENTS ...............................................................................

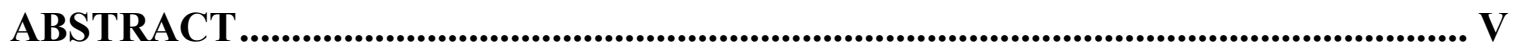

LIST OF ABBREVIATIONS ................................................................................ VII

1 COLLABORATION IN STORYTELLING ............................................................. 1

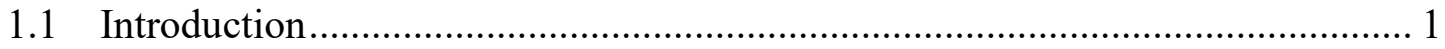

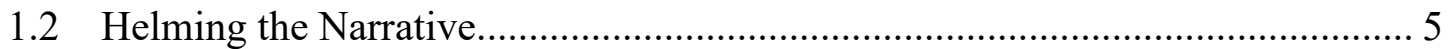

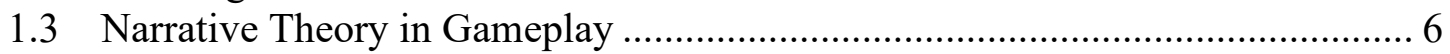

1.3.1 Choice and Consequences................................................................. 8

1.3.2 Revolutionizing Storytelling.............................................................. 10

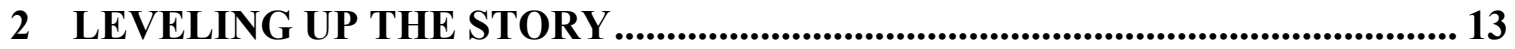

2.1 Adapting to a Freeform Narrative ................................................................ 13

2.2 Applying Experience in Pedagogy …………………................................. 19

2.3 Pursuing TTRPGs in Composition ................................................................ 26

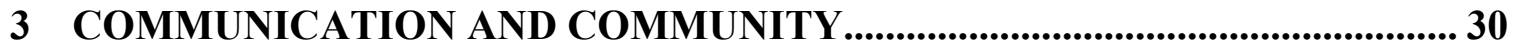

3.1 Take A Chance, Roll The Dice …………………....................................... 30

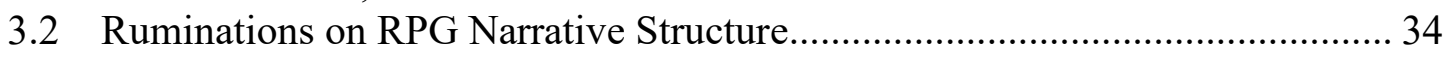

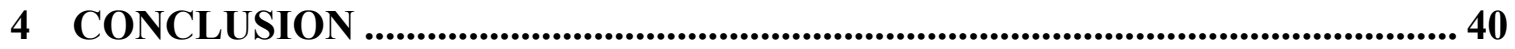

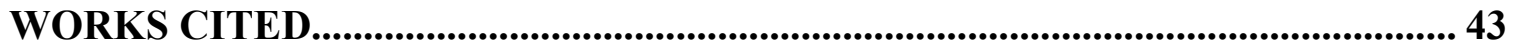

APPENDICES ................................................................................................................. 45 


\section{LIST OF ABBREVIATIONS}

$\underline{\text { Abbreviation Meaning }}$

$\begin{array}{cl}\text { ARP } & \text { Action Research Project } \\ \text { CoM } & \text { City of Mist } \\ \text { D\&D } & \text { Dungeons and Dragons } \\ \text { FYC } & \text { First Year Composition } \\ \text { MotW } & \text { Monster of the Week } \\ \text { NPC } & \text { Non-player Character } \\ \text { RPG } & \text { Roleplaying Game } \\ \text { ToC } & \text { Table of Contents } \\ \text { TTRPG } & \text { Tabletop Roleplaying Game } \\ \text { V:TM } & \text { Vampire: The Masquerade }\end{array}$




\section{Collaboration in Storytelling}

\subsection{Introduction}

"The crowd around you is roaring in excitement. You feel the ground rumble beneath your feet, a single moment's warning before the massive creature bursts forth in a shower of dirt and snow. An aura of ice and freezing cold emanates from the frost salamander's blue skin, its head whipping back and forth as it surveys the ring and tracks all your positions. Penter, you're the closest. It's going to make a bite attack against you... Does a 22 hit? Okay, that's 18 points of piercing damage and 8 points of cold damage. It moves 20 feet closer to you, Khallisa, and ends its turn. Filipa, you're up next... what do you do?"

Things were tense. We were three hours into our weekly Dungeons and Dragons game and had just reached the crux of the night's game. I leaned forward eagerly, wondering what my players would do to counter the monster. This game was our escape as much as it was our outlet; though we were separated by distance and covid-19, we still logged into our weekly Google Meets call to engage in fantastical storytelling and the rolling of innumerable dice. My friends are incredibly resourceful players, always coming up with the most creative and outrageous solutions to the various challenges I throw at them. Now just over three years into this campaign, which was my first ever foray into helming such an endeavor, we were deep into the current arc's primary conflict: a high-stakes tournament, in which adventuring parties competed for the championship title - and an impressive sum of gold. I smiled, thinking I was prepared for whatever Filipa's player came up with for her turn. She read over her character sheet, checking spell descriptions and abilities. Then, her face lit up. 
"I cast Polymorph and try to turn it into a goldfish."

That... was definitely not what I'd expected. At all. I chuckled, looking at the monster's stats as I rolled its save against the effect. And, as the storytelling gods would have it, the monster failed. The players laughed and cheered as I replaced the giant lizard token on the map with a tiny image of a fish I'd had to spend a minute searching for. But the big threat was temporarily incapacitated, and the rest of the fight went almost too smooth. Victory in hand, the session wrapped for the evening and we all spent a few minutes joking about how badly that could've gone had the monster succeeded the roll before bidding each other goodnight and ending the video call.

What that night's session had demonstrated was the profound, inescapable draw of tabletop gaming - one that isn't found in any other storytelling medium. While there are dozens of rule systems, world settings, and narrative frameworks to choose from, all roleplaying games attribute their appeal to the immense creative freedom and interactivity this form of storytelling structure offers. Long has the notion of crafting stories been steeped in the practice of an individual author toiling away in relative isolation, their creative genius unseen by an eager audience until the day the completed story is ready to be shown to the world. Kids and adults, hobbyists and professionals, students and educators, all conform to traditional narrative norms and typical genre conventions found in linear narrative structures. Few eyes outside of the author are allowed to behold the drafts for fear of criticism or theft.

In the case of traditional single-author narratives, the manner in which the story is drafted and completed often leaves little room for audience participation or influence. The character beats and story progression take form from the author's mind, possibly not seeing input or suggestions from beta readers until at least a first draft is finished; although the story might 
change significantly after rounds of revisions and feedback, the eventual audience to which the finished narrative will be released still has relatively minimal interaction with it beforehand. More collaborative narrative structures, such as the film industry, have somewhat broken from this single-author mold by drawing on teams of creatives to write, direct, and produce their stories. Social media allows fans to discuss their thoughts and reactions to media, sometimes even directly with the ones in charge of story direction, thus allowing a deeper level of interactivity and communication between the creators and their audiences. The gaming industry further pushes these limits with massive teams of programmers, artists, and game developers working to continually improve upon programs and systems in which players can feel that their in-game choices have a real impact on the story's direction.

And yet, there is still a certain lack of freedom of choice. The options players are given are most often restricted in their impact by predetermined outcomes, planned pathways that may meander and intersect with each other, before ultimately converging into a limited set of conclusions. Some video games, such as Detroit: Become Human, The Wolf Among Us, Until Dawn, and Bioshock have made names for themselves by promising that player choices during gameplay can affect the outcome through interactions with the world and the characters within, encouraging people to think before they act and consider the consequences of their actions. In theory, it's revolutionary. But in the end, the story is still planned for the players.

Collaborative storytelling draws strength from the contributions of those involved with crafting the narrative. Digital and tabletop roleplaying games are among the most successful forms of evolving narrative structures, in which everyone involved is actively shaping the story in real time, reacting to each other's decisions, dealing with the short and long-term repercussions of their actions, and helping guide the story towards an eventual conclusion. 
Digital games such as Second Life, Elder Scrolls Online, League of Legends, World of Warcraft, and other online multiplayer games allow players to create their own characters, choose their roles in the worlds, and participate in both individual and collaborative storylines. However, while digital games are often ruled by programmed artificial intelligence making decisions in reaction to player actions, tabletop RPGs are primarily reliant on a human hand guiding the narrative. This allows for a level of mediation between participants, ensuring the players can exert influence over the world they're interacting with while still accommodating and subverting restrictions. The rules under which TTRPGs operate can vary greatly depending on the game's system and setting, but the rules can be less rigid than traditional narratives. According to Katie Salen and Eric Zimmerman, "when play occurs, it can overflow and overwhelm the more rigid structure in which it is taking place, generating emergent, unpredictable results. Sometimes, in fact, the force of play is so powerful that it can change the structure itself' (301). This is what makes collaborative storytelling in TTRPGs such innovative forms of narrative - and why using TTRPG systems in personal and pedagogical endeavors can be an immense benefit to craft and creativity for those involved.

Drawing from my own experiences as a participant in various TTRPG games, I emulated a TTRPG-like interactive activity into composition pedagogy to observe the reception of collaborative storytelling and possible creative growth of my students in a university-level FYC course. Taking into consideration the many variables and factors of the somewhat freeform, somewhat restrictive RPG structure in my assignments, I studied existing applications of narrative theory in gaming when positing that the narrative structure of TTRPGs offers not only an innovative form of creative and collaborative storytelling, but also a useful means of challenging students' abilities to accommodate and communicate with their peers. 


\subsection{Helming the Narrative}

The draw of RPGs lies primarily in the sheer amount of freedom the narrative structure offers. Most games are built with a progression system in place thanks to the rules, the setting, and the kind of story the system encourages people to act out. The one in charge of running the game, often referred to as the Game Master or Dungeon Master, rewards their players for their progress through the various story arcs by allowing the characters to level up, gain new abilities or powers, or other similar mechanics. While reading a book or watching a movie might reward audiences with narrative payoff, there is still a level of disconnect with those characters. In TTRPGs, the players are inhabiting their characters, directly connecting to their growth over the course of the game. And there's more to a game than simply sitting around a table, rolling dice and checking pieces of paper as the characters fight monsters, gods, and sometimes each other. When friends gather together for hours at a time to laugh, cry, joke, and groan, the games they play and the stories they tell can help stave off loneliness, isolation, even depression for a time.

With just how unconventional an RPG's narrative structure can be, progress itself can feel uneven at times. Pacing can fluctuate from plodding to action-packed as players brainstorm, problem-solve, and improvise in real time, reacting to story threads, plot hooks, puzzles, or threats they encounter. Unlike a novel or a movie, the players are all contributors to the story on a level almost equivalent to the GM who crafted the idea. Reactions and creative input help drive the direction and the momentum as players guide their characters towards a conclusion that, while not always predictable, is satisfying. The most successful campaigns reach these conclusions because the balance and agreement struck between the GM and their players is mutually accommodating, ensuring every participant comes away pleased with their decisions. 
Both sides must be able to give and take, act and react, and be aware that some actions won't please everyone. Mediation and communication are key to running a successful game.

When it first debuted in 1974, Dungeons and Dragons brought magic and medieval aesthetics to the forefront; heavily influenced by JRR Tolkien's Lord of the Rings series, D\&D had no small role in helping to kickstart and innovate TTRPGs over the years. For all its popularity, though, D\&D isn't the only game available. For people seeking to play mystery solvers with genre-savvy tropes, Monster of the Week boasts a more serialized storytelling format not unlike weekly television shows with a unique mystery each session. Ever wanted to play a demigod-like character? The more recent City of Mist setting lets players inhabit everyday characters who are suddenly able to wield great and powerful abilities inspired by myth and legend. And horror lovers will feel right at home with Call of Cthulhu, influenced by the works of HP Lovecraft. There are countless genres to play in, each offering specialized gameplay and potential narratives, and RPGs have been the center of numerous articles, studies, theories, and literature over the many decades they've existed.

\subsection{Narrative Theory in Gameplay}

The majority of theorists, such as Espen Aarseth, Gordon Calleja, and Christopher Goetz, focus primarily on studying the applications of narrative theory and interactivity in video games and digital RPGs rather than TTRPGs. Much of the existing discourse involving game and narrative theory questions if video games actually qualify as acceptable narrative structures on the same level as traditional writing. The unconventional, nonlinear choice-based systems in which many digital - and tabletop - RPGs function makes it difficult for scholars to properly evaluate just how cohesive the story is or what the proper progression should be. The fact that 
the main plot can often be ignored in favor of side quests, that objectives can be incrementally completed, or that certain parts of the story can be outright skipped or fulfilled out of order, shatters the idea that a narrative must always be moving in a linear, forward path. Then, throw in the improvisation, problem-solving, and reactionary nature of facing consequences that is hardwired into RPG progression. Narrative games are multifaceted, and thus are incredibly complicated when it comes to dissecting just how everything weaves together. However, since digital and tabletop RPGs are quite similar in many ways when it comes to story progression, choices, and consequences, some conclusions and studies that have been conducted on digital games can be applied in theory to tabletop games as well.

Most studies and theories conducted on RPG systems focus on the relative freedom players are offered while progressing through the game. Traditional narrative limits audience participation to mere reactions after the fact, and thus the audience has no influence on the story. In contrast, RPGs inherently function on player participation and influence to direct the story; the resulting consequences of their decisions then shape the narrative up to, and sometimes beyond, the conclusion. In his article "A Narrative Theory of Games," Espen Aarseth directly confronts the ongoing discourse surrounding digital games by asking "do theoretical concepts such as 'story,' 'fiction,' 'character,' 'narrative,' or 'rhetoric' remain meaningful when transposed to a new field, or do they turn into empty, misleading catchphrases, blinding us to the empirical differences and effectively puncturing our chances of producing theoretical innovation?” (129). His theory posits that yes, digital games can be a type of narrative even if they do not fit the traditional, linear structure seen everywhere else. He argues that games can be a successful medium for storytelling depending "on the question of whether games can be considered narrative at all, but rather for (future) criticism and, above all, creative innovation" (Aarseth 
130). Narrative theory, in Aarseth's perspective, should look at the fundamentals of storytelling and what drives the narrative: deep, interesting characters and rich settings. That, of course, is where RPGs can and should excel. But whereas RPGs share characterization and worldbuilding with traditional narrative, it is the impact of player choices that set their narrative progression apart.

\subsubsection{Choice and Consequences}

In 2018, the journal Gaming and the Arts of Storytelling published a special issue focused specifically on interdisciplinary approaches to narrative design in digital games, to further the discourse on what makes choice-based systems so unique. One of the articles in this issue, "Choice Poetics by Example," was written by Peter Mawhorter et al as an expansion of a previous article on their theory of choice poetics. The theory of choice poetics is defined as a "formalist framework that seeks to concretely describe the impacts choices have on player experiences within narrative games... and emphasizes the need to account for players' various modes of engagement, which vary both during play and between players" (57). Their article focuses on the kinds of choices players are asked to make while engaging with digital RPGs: explicit choices that can drastically alter the direction and outcome of the narrative, and subtle choices that may not impact an ending but can alter smaller interactions with and behaviors of nonplayer characters. Mawhorter et al conducted a series of studies on player choices, hoping to figure out "the impact of narrative choices on the player via their options, their outcomes, and how those relate to player goals" ("Choice Poetics" 57).

In theory, players make choices in RPGs based on the outcome they're most interested in seeing, rather than what might be proposed as the "correct" choice by the current narrative based on the implied consequences of certain actions; however, if the consequences of those choices 
end up not being what the player wants, digital RPGs offer the ability to backtrack by replaying the game or loading a previous save file to then make a different choice. This can lead to multiple playthroughs of a game over time as players explore different choices to see different outcomes, driven then by curiosity rather than intent. Through studying player reactions to two games whose outcomes alter based on in-game decisions, Undertale and Papers, Please, Mawhorter et all were able to break down variables that affected choices and reactions such as players' initial goals with the story, conforming to or resisting the "correct" choice based on narrative pressure, and personal play styles. Their theory "helps pinpoint exactly which outcomes drive that separation [of play styles], and what sets of priorities are necessary for it to happen" (“Choice Poetics" 69).

The theory of choice poetics presents a fascinating exploration into the psychology behind decision-making, although the conclusions are still restricted by game mechanics and prescripted narrative directions. There is only so much freedom the players are afforded, and while certain choices lead to certain endings, the overall influence a player can exert on the story itself is comparably minimal to that of tabletop games. Digital games are pre-written, packaged, and shipped as complete, choose-your-own-adventures. Tabletop games, on the other hand, are written as they're played and unlike their digital counterparts often prevent players from backtracking or retconning their choices. This is why it is key for a GM to know their players well, so they can be prepared for certain kinds of play styles and personalities that will influence the story's direction. Players more interested in combat might not be as concerned with the consequences of their killing and plundering as players who are more interested in inhabiting their characters and interacting with the world and the NPCs around them. Ignacio Dominquez at al, in their article "The Mimesis Effect: The Effects of Roles on Player Choice in Interactive 
Narrative Roleplaying Games," further defined narrative interaction within RPGs with their own studies. In this article, they concluded that "it is more likely for players to choose actions aligned to roles afforded by the game, which suggests that crafting content aligned with those roles can be used as a way to mitigate the authorial combinatorics problem of interactive narrative" (3447) - the authorial combinatorics problem being the overall time and effort the author, or GM, is putting into the game.

There are so many layers to a tabletop game than observers may realize, especially when compared to digital games. Where a digital game has entire teams of designers and programmers to brainstorm and playtest for issues, bugs, and quality assurance, tabletop games have no such means. Therefore, TTRPGs depend on an entirely different kind of creative team when it comes to execution of the narrative.

\subsubsection{Revolutionizing Storytelling}

RPGs, like any storytelling medium, lean on tropes, stereotypes, and generalizations in lore and worldbuilding. Some games might be genre-savvy or meta about their gameplay, being self-aware in the rulebooks or gameplay itself. But it is both the duty of the game designers and the game's participants to be aware of potentially problematic or harmful depictions of race, culture, society, and aesthetics within the system and setting. Being able to voice these concerns and address these issues is what leads to updates and revisions, making games more accommodating for their audiences while addressing their faults.

In January 2021 Dicebreaker.com ran an article titled "Vampire: The Masquerade Shows the Right Way to Confront an RPG's Problematic Past," which was written in response to the somewhat lackluster efforts from Wizards of the Coast, D\&D's parent company, after they hyped up their new expansion rulebook to combat issues with playable races in previous 
editions. Where fans of D\&D were expecting a substantial overhaul and redirection of character creation and racial traits that helped determine gameplay, the rulebook simply suggested that players could choose to ignore certain traits and abilities, swapping them for others in a customizable character origin. In contrast to the rulebook, the article discusses the updates Vampire: The Masquerade was working on in its own system. In V:TM, players can choose from "clans" of vampires to determine their character and playstyle - like how in D\&D, players can choose from an array of fantasy "races" like humans, elves, dwarves, and orcs. One problem that plagued previous editions of V:TM was one clan, the "Banu Haqim," whose skin "grows darker as they age, a process which often means their compassion, empathy, and humanity [is] slipping away from them. Their skin literally got darker as they became more evil - a metaphor as subtle as a sledgehammer that perpetuated harmful ideas of anti-Blackness in the community" (Trivedy). What set V:TM's efforts apart from Wizards of the Coast, however, was that the writers decided to start from scratch with their update, rewriting and restructuring the game to do away with such stereotypes and descriptions. Granted, D\&D is a massive franchise and making such alterations would be a massive undertaking, but the stark contrast in efforts to update problematic aspects of the game stands out. The article concludes by reiterating that "racist stereotypes are not interesting lore, but a limit on player creativity. More than that, they are a barrier to marginalized people feeling welcome in your game."

What further sets TTRPGs apart from traditional storytelling, and from digital RPGs to an extent, is how interactive the communities are with each other and with the game designers. Authors are somewhat limited in how exactly they can interact with their fans and followers when it comes to discussing their stories - novels, short stories, films, television, they're essentially untouchable once they're finished and released to the public. If fans are dissatisfied, 
they turn to fanfiction to create alternate storylines to appease themselves and others. With serialized stories like TV shows and podcasts, the episodes are pre-recorded, edited, and shipped beforehand so even if creators can interact with fans "live" as new episodes drop, nothing is being changed.

TTRPG communities have also revolutionized creator-audience interaction to a certain extent. The advent of actual-play games like Critical Role; Acquisitions Incorporated; Dice, Camera, Action!; and High Rollers, which are all D\&D campaigns streamed live weekly on Twitch, have allowed fans and players alike to discuss the consequences of the players' actions on the ever-changing and unpredictable story directions on a level unlike any other medium. And, with streaming capabilities and live chat boxes, some games even allow audiences outside of the players themselves to also influence the story by pausing the game to hold votes on certain narrative details like a random monster appearing, a character suddenly changing races, or other shenanigans. 


\section{Leveling Up The Story}

\subsection{Adapting to a Freeform Narrative}

"Running a campaign is no big deal," I say to myself as I scroll through the dozens of Google Doc pages, Word documents, and OneNote folders that contain all my notes, characters, lore, and campaign information. "It most definitely won't consume all your free time and imagination."

Helming an RPG campaign is no simple task. It's easy to underestimate the amount of time and the level of imagination required to even begin planning a game. It's difficult to shift gears from complete ideas to constantly changing, interwoven plot threads when sitting down to map out story arcs. And it's nearly impossible to predict where the story will actually go. As I look through the story arcs I'd brainstormed, the outlines I'd penned, the possible side quests and tangents my players could explore, I take stock of how many have been abandoned, torn apart, restructured, and adapted over the course of the game. Normally, such chaos would be frustrating for me as an author. I like plans. Having an outline, a goal, and a direction makes writing so much easier because I know what's going to happen - I have contingencies, solutions, dialogue all drafted up and ready to go. But running a D\&D campaign required me to throw out all of my previous expectations and experience in how to craft a narrative. I had to improvise and adapt scenes, characters, and dialogue on the fly. The clever foreshadowing and hint-dropping I thought I'd woven so cleverly into the plot often went either unnoticed or was laser-focused on. What I'd planned as the most obvious path forward for my players never even occurred to them as they discussed how to proceed. In an exclusive interview, avid D\&D fan and voice actor Amy 
Vorpahl talks about her contributions to the upcoming Candlekeep Mysteries adventure book, explaining that "adventure writers are actually crafting a playground rather than a story. Littered with toys and tools like a jungle-gym of the imagination, it's an invitation to come play - or not, as they case may be. That's the hardest part about writing your own D\&D campaign: knowing that chunks of your hard work are going to be missed or ignored" (Abbott). What a GM might expect their players to love or enjoy might backfire entirely, if they're not very lucky. The grand plan might be obliterated by a lucky roll of the dice. And it's up to the GM to pick up the pieces and put them back together into something even better.

Almost all of my writing experience prior to getting into TTRPGs was literary. The majority of classes I'd taken throughout my academic career were focused on composing short stories, scripts, and novels. I was used to the linear structure, the clear direction of where a story should be going, the clarity of knowing exactly what would happen and when. I was in control of the world, the characters, and ending. As much as I enjoyed the creative process, however, it still felt isolating. I'd often reach out to one friend or another, asking them if I could bounce ideas off of them or if they'd have the time to be a beta reader.

I've always been a strong advocate for writers needing a sounding board. This could be a workshop or writing group, close friends who are able and willing to provide constructive criticism, or even just a trusted acquaintance who is patient enough to sit on a three hour Skype call and listen to me ramble out the plot of my latest novel. In a way, a writer's sounding board is just like the rubber duck method employed in programming. This method refers to when an engineer or programmer explains their task to a rubber duck or similar inanimate proxy in detail, line by line. By describing the problem or issue, they are forced to express their process clearly and slowly, often allowing them to catch the bug in the programming they might have otherwise 
missed. For writers, a lot of subplots, character details, and worldbuilding can slip through the cracks during the outlining and writing phases, leading to frustrating plot holes and unresolved threads that won't be caught until beta readers get their hands on the manuscripts. When a writer finds they're struggling with a plot hole, having to explain the story in precise detail to another person - the rubber duck in this situation - can let them catch the issue.

In TTRPGs, the GM is not the sole author, however. The risk of plot holes and inconsistencies is much lower because the sounding board, the chorus of rubber ducks, is at the table with the GM to offer their input. Unlike the solitary writer toiling away on their lonesome, a campaign is built through collaboration and communication in real time. Even if the GM has plotted a scenario, like I thought I had with hosting the tournament in my campaign, they can be blindsided by an errant player choice and are utterly lost with how to proceed. The narrative risks being lost, the momentum of the story grinding to a halt. I find that running a game has pushed my creativity and improvisation to the limit, far outside my comfort zone. No longer the sole author of my world, there was simultaneously more and less direction of where our narrative would go and how it would unfold. Though I was ultimately in charge of the overarching journey, my players were the ones directing the immediate actions. The benefit of this, however, was their active input whenever I was stalled.

In 2010, Jennifer Grouling Cover published The Creation of Narrative in Tabletop Roleplaying Games - an exploration of her own experience playing in a D\&D campaign during her time as a graduate student. Fascinated with narrative analysis, she found herself at odds with the traditional definition of a story being told by a narrator to an audience. She, too, questioned whether TTRPGs could really be considered narrative, and through her book analyzed the many aspects that fed into a campaign. She found that when the narrative stalled on the part of the GM, 
there was a simple phrase that allowed the players to take agency and keep the story moving as coauthors: "when players are posed with the question 'what do you do?' they are given the opportunity not only to make decisions but also to build their own pathways. This is especially true of home games and longer running campaigns" (Cover 30). A TTRPG story is built in the present rather than told in the past.

For a novel, I'm responsible for every choice, every mistake, and every conclusion made in the narrative. I'm constrained by the linearity of progression, often unable to explore subsequent ideas that might have cropped up throughout the writing process. Tangents take time away from the primary plot, and I've had to kill many a darling to stay on track. But when planning my campaign, I could ignore all those rules. I was free to create dozens of characters who might not even show up "onscreen" but still existed in the background as active entities. I could write in-game myths and legends for my players to uncover, leaving the door open to possible side quests and tangential adventures if they chose to pursue those directions. There was lore for items like weapons, armor, and magic-infused objects to help them or hurt them. And, when I started to run dry of ideas, my players would approach me with the most glorious of phrases: "what if...?"

Even the act of shopping, with my players' characters wandering into a random store I'd have to dream up on the fly and interacting with the enigmatic shopkeeper boasting exquisite wares, led to fulfilling encounters and fun interactions. Gordon Calleja, in his book In-Game: From Immersion to Incorporation, wrote that "even the most basic of game operations generate[s] narrative segments that contribute to the overall narrative experience" (129). Though his focus was on digital gaming and the incorporation of a player's narrative involvement into pre-scripted actions, he also took into consideration the strength of TTRPGs as opposed to digital 
RPGs when analyzing interactivity. In digital games, players are restricted in what they can interact with - the NPCs, the objects, the environment - and can often be frustrated with being locked out of certain actions. This could be as simple as seeing a cool weapon displayed on the wall of an in-game shop that isn't interactable or buyable, or it can be as complex as wanting to romance an NPC that the player isn't able to even speak with. The player's immersion in the game is disrupted in such scenarios, but in a TTRPG, that cool item or NPC might be a simple persuasion roll away, allowing the GM to maintain the involvement and immersion of the player.

In a digital game, a player wanting to purchase a certain item might need to have achieved a certain level, completed a specific quest, or fulfilled some other requirement before being allowed to do so. The mechanics, the code, of the game prohibit the purchase otherwise. In a tabletop game, a player wanting to purchase an item that's too expensive or trying to convince the shopkeeper to trade it for something else might be asked to make a persuasion or intimidation roll. As Calleja says, TTRPGs are exemplary because "the mechanical workings of the system are transparent to the players and game masters, since they are expressed in numbers that are made meaningful through the cognitive interpretation of the rule system. Digital games hide these calculations within their layers of code" (203).

A digital game that emulates a tabletop game's random probability, like the Baldur's Gate series which actually include an in-game dice rolling mechanic, still poses the challenge of once the dice is rolled, the outcome is solidified in the code and the game moves forward. There are few, if any, opportunities to backtrack or try again without reloading a save or starting a new game. If the player fails, they might feel punished because they can no longer pursue that story or quest. A tabletop game, however, isn't run by a computer but a person. Even if a player fails, the GM can take pity and let them try again so far as the game system permits. The relatively 
new system, City of Mist, introduces a mechanic to gameplay in which players can work together to build up statuses and conditions against an opposing force, so that even if one roll fails to make forward progress, another player's success can make up for it. I think of these mechanics as "failing forward" in that just because the dice say my players failed, it doesn't mean their efforts were for naught. Jennifer Grouling Cover also noted this in her own experiences, observing why tabletop games far surpass their digital counterparts when addressing failure. She asks, "why have TRPGs persisted when their generic cousins have been replaced by new media? ... Players are more often than not rewarded rather than punished for creativity, and the social structure of the game allows for flexibility that is simply not possible in even the best new media texts" (34).

Essentially, tabletop games can be so much more rewarding when the story culminates in narrative payoff. To sit there and narrate the beheading of the evil orc leader, the fall of the demon army, or the sealing of a corrupt god and watch my players cheer and cry as their efforts are rewarded is an experience unto itself. A novel might make a reader tense as the protagonist faces down their enemy, might even make the reader sob uncontrollably as the protagonist is reunited with their family as a result of their success, but they had no direct interactions with the narrative. There is a lack of personal stake in the story. The author can sit next to their reader, watching them get to that part of the novel, or they can host a reading of the novel to an audience and see their reactions in the moment, but there's still that cognitive and narrative distance. My players aren't just reacting to the story as I tell it; they're actively invested in the growth and survival of their characters, excited to enact change in the setting's status quo, and determined to see their journey through to the end. If they don't like where I'm implying a story might go, they can take steps to influence and change it to something better or more interesting. If I'm not 
happy with the story I've been struggling to tell, I can ask them what they'd prefer to see. The social interaction and feedback we give each other propels the narrative onto another level. And it's something that has fueled my creativity and imagination far more than any novel or short story I've written to date.

\subsection{Applying Experience in Pedagogy}

Collaborative work has long been a staple of pedagogy and academia, primarily in the form of group projects for students and coauthoring papers for professionals; but for students, those collaborative assignments can often be dry, limited, and not very creatively fulfilling. Additionally, such collaborative assignments aren't valued much in academia and are relegated to small-scale presentations or discussions rather than big projects. Up until they reach university or college, and even during that time, the majority of students have probably worked individually to write stories and papers. In both composition and creative writing classes, most opportunities to work together might be lumped into workshopping in-progress or completed work, breaking down larger reading assignments into group analyses to be presented at some point, or class-wide brainstorming in the earliest stages of planning ideas. As a student, I appreciated these collaborative moments even as they were few and far between because it gave me the chance to give and receive feedback, to allow my peers to catch the plot holes and inconsistencies that I missed, and to hear their conjectures on where the story was headed. Sometimes, a classmate would voice an idea that I liked better than the one I had in mind, and I found myself wishing I'd come up with that instead.

So, when I had the opportunity to design and teach my own class as a graduate teaching assistant, I wanted to bring my own experience as both a creative writer and as a GM to the 
classroom. As part of my first semester teaching this course, I conducted an Action Research Project on how my students engaged with their peers in collaborative, creative projects designed around an RPG-like framework.

As part of this project, I looked into existing research and theories revolving around collaborative learning and applying TTRPG narrative structure to rhetoric and composition. In Collaborative Learning: Higher Education, Interdependence, and the Authority of Knowledge, Kenneth Bruffee posed a collection of observations and studies conducted by college and university professors who sought to include more collaborative methods into their teaching. Published in 1999, some of the research methods and conclusions are a bit outdated now thanks to improvements in technology used in several studies - however, many conclusions drawn in this book provide a solid basis for my own intentions. Bruffee considers collaboration a form of negotiation that arises when members of a community engage with one another, as well as those on the outside of the community who may wish to join. That negotiation, in part, refers to communities formed by professors and their colleagues, and the student communities that are formed in classrooms and on campus. There's an exchange of knowledge that occurs in academia: professors are passing along their knowledge and expertise to their students, some of which probably don't have a basic understanding of the topics before taking those classes.

Collaboration, therefore, applies to not only students being able to communicate with each other, but professors being able to engage with their students on the same level. Encouraging students to engage with their peers during class time through projects, answering each other's questions, and talking to each other like equals is a challenge professors must be able to overcome. As Bruffee explains, “... students do not always work effectively as collaborative peers, especially at first. First, given most students' almost exclusive experience of 
traditional classroom authority, many have to learn, sometimes against considerable resistance, to grant authority not to the teacher alone but to a peer instead of the teacher. They also have to learn to accept the authority granted to them by a peer" (14). Most resistance students feel is when they're launched straight into group work without having been given the time to get to know each other and feel comfortable with each other's styles.

Knowing the right time to introduce such projects is key. In A Guide to Composition Pedagogies, Krista Kennedy and Rebecca Moore Howard, who worked together to write one chapter, maintain that collaborative assignments "should not be begun until a substantial portion of the term has elapsed. In the interim, pedagogy should be sufficiently collaborative that the students get to know each other, resolve some of the small interpersonal tensions that inevitably arise, and anticipate each other's collaborative assets and shortcomings" (39). Just as TTRPG players must be communicative with each other, so they are able to work around each other's expectations and play styles, so too must students working together know what to expect with dividing work and responsibilities among their group.

Applying TTRPG narrative theory and techniques to pedagogy can be daunting and difficult, but not impossible. It may seem improbable to try and teach students how to play the games, or even to expect all of them would be interested in such projects, but therein lies a fun challenge for the professor. The open-world creativity of RPGs offers a myriad of creative writing opportunities and potential assignments. Rather than asking students to learn an RPG system, professors can adapt the loose narrative, collaborative structure into group prompts and encourage their students to work together in crafting a story, with each of them being able to contribute to the direction and execution. These projects, in turn, can then help students grow and reinforce their skills in creative thinking, improvisation, and mediation when working with their 
partners to meet deadlines and contribute to the overall assignment. Ian Bogost, in "The Rhetoric of Video Games," discussed how games - in his specific case, video games - are not often considered legitimate avenues for teaching because the act of playing is considered childish or distracting. He starts by describing that "play and learning have been segregated from one another in contemporary schooling, further cementing their perceived disparity. Children learn while seated at desks, listening attentively to a teacher or reading from a book... play is a distraction useful only to letting off the necessary steam to allow kids (or adults) to get back to the serious business of learning (or working)" (120), but argues that this assumption tends to be a misunderstanding of the act of playing. Games and their inherent rules provide a structure and system, much like an assignment's rubric, and giving students the chance to emulate a game allows them to explore, manipulate, and possibly subvert the assignment's limitations as they work together to tell the story. Though Bogost is specifically referring to video games in his article, much of his theoretical framework can be extended to the basics of TTRPG play.

While designing the collaborative assignments in my course, I wanted to try and avoid the "dreaded" group projects that students often fear - mostly because there's the inescapable concern that one person won't pull their weight and leave the work to the others. There would be a slow but gradual ramping up of how involved creatively my students would get with their work. The first major project was a presentation: in groups of 3 , students would do a bit of research on a story of their choice, work together to make a presentation of some kind, and then individually write a 2-3 page reflection letter on how it went. My intent was to get them warmed up to the idea of working with each other, so I allowed them to choose their own groups. For the most part, it made them all much more comfortable with each other's work ethics and styles. This then led into the collaborative workshops, where my students would present a piece of their 
writing to each other in slightly larger groups for feedback. I noticed that most of the groups from the presentation got back together for these workshops, which seemed to track with the mostly positive feedback individual students had for each other.

When it came time to assign on the big two collaborative assignments, I felt that I'd given enough time for my students to get comfortable with each other. I took inspiration from “Trellis and Vine: Weaving Function and Fiction in Videogame Play" by Christopher Goetz. In his piece, Goetz described how to envision a narrative's relationship to the game's structure: the "trellis" being the structure, rules, or programming while the "vine" was the story being woven around those limitations. He described his theory as "the trellis is artificial, rigid, inert, mechanically repetitious in structure, and incomplete on its own (deliberately gap-filled); the vine is organic, dynamic, unpredictable, goal driven, and can be taken to new heights by the support the trellis offers. The vine may, of course, ignore the trellis altogether...” (30). In my case, the "trellis" was the prompts themselves - I had rules, expectations, and rubrics attached to them, creating a structure for the students to write their narrative around - while the "vine" would be the story they'd work together to tell. For the prompts, I drew inspiration from Monster of The Week, an RPG setting in which players create paranormal investigators of various backgrounds and professions that work together to solve dangerous mysteries. Since my class was a seminar covering rhetoric in paranormal genres, I figured using this RPG's basic structure was a good way to introduce my students to a freeform, collaborative type of storytelling. For these two linked assignments, they had to once more choose small groups to work in, coming together to brainstorm and write.

The first prompt was, appropriately, a character-building activity (see Appendix A). Just as a player would create their character in an RPG, my students would work together to create a 
party of paranormal investigators - complete with names, personalities, backstories, and skills to bring to their investigation. Though they weren't filling out actual character sheets, I had the students submit short profiles detailing who they would be "playing" in the second prompt. I was apprehensive of assigning these writing exercises in the weeks leading up to it, primarily because of how ambitious it felt. As much as I think actually running a game for my students would've been incredibly fun (though unbelievably complicated), I figured not all of them would have the time or interest in learning the system, creating characters, and having the resources to play a full game. Plus, the class was just too big to make that practical. So, I sat back and crossed my fingers as I sent my students into their Zoom breakout rooms. As the due date passed and the submissions rolled in, I was more than pleasantly surprised to see well-rounded, interesting character profiles ready to go. It seemed to go over very well. Now it was time for the second, and much more daunting, prompt.

The second prompt (also located in Appendix A) was having my students work in their groups to tell a story. Seems fairly simple, right? The groups would meet and agree on a "mystery" for their characters to solve: were they investigating a haunted house? Maybe a strange monster was haunting a sleepy little town, children would disappear without a trace on the nights of a full moon, or rumors of a crashed alien spacecraft had reached the investigators' ears. Once they'd settled on the mystery, the groups would then have to figure out how they wanted to tell this story. Like an RPG, there would be "beats" to the story they'd have to get to, leads and hints to follow up on, and agree on a mutually satisfying outcome for their characters. Though there would be no dice rolling or GM calling the shots, they were essentially playing a GM-less game. I watched and listened as my students devised incredibly clever narrative styles in which to tell their stories - one group decided each character would write in diary entries, and 
the audience would have to read the entries in the correct order to piece together how their ghost hunt went wrong; another group recorded a podcast, structured as their amateur high-school alien enthusiasts giving testimonies to the police after one of their friends was seemingly abducted; and a third group came together in a makeshift "gaming session" to write in a Google Doc the harrowing tale of their escape from an alternate dimension filled with strange creatures that wanted to keep them there forever. I was surprised by the level of creativity unleashed by the lack of a traditional, linear narrative structure. It was by far the most successful writing assignment I'd given them the entire semester, and even the students who didn't feel they were good writers wrote in their end-of-semester reflection letters that they'd loved these prompts.

As I collected their testimonies and reflections for my research project, I paid close attention to their feedback on the collaborative aspects of the course. At the beginning of the semester, over half my class cited concerns about time management, leadership skills, and communication issues (most relevant, as it was an online class due to covid-19). When asked how comfortable they felt working collaboratively, they weren't certain how to approach the more creative assignments since there was less structure and direction; up until that point, I felt it was safe to assume my students had very little experience with RPG-like storytelling. But, as the semester closed, their responses changed drastically. There were noticeable improvements in their personal work ethics and writing styles, and a number of them included an interest and enthusiasm in pursuing collaborative work for both academic and creative projects going forward. Though we were separated by distance and technology, making the fostering of a classroom community and interpersonal relationships between my students incredibly difficult, they overcame those obstacles to great success. My intention to use RPG-like assignments to help foster those creative connections between my students seemingly paid off, and my research 
project's hypothesis that collaborative storytelling rewarded students for breaking free from traditional, limiting narratives was proved to be on the right track.

\subsection{Pursuing TTRPGs in Composition}

Tabletop games are built on communication and collaboration. Each contributor to the narrative has to demonstrate critical thinking as well as imagination. The process of planning and playing games is similar to outlining and writing essays in that it takes time to plot out the main points, skill to figure out pacing, working out when and how to introduce a new concept to the playing field, and making the whole thing feel cohesive as a narrative. My ARP was conducted in a First Year Composition course, in which I wanted to build my students' creative and critical thinking skills through challenging their preconceptions of how to construct a narrative. In his 2017 dissertation, Timothy Woods addressed the novelty and importance of introducing TTRPG games into classrooms to foster student growth in an FYC. He posited that "composition classes, especially the FYC course, must respond to the writing needs of the learners, rather than a strictly instructor-driven curriculum. The emergent learning which TRPGs encourage allow the compositional inclinations, and deficiencies, of the students to become the focus of the course" (Woods 148). Just as a TTRPG's narrative must be malleable to the desires of the players, so too should an FYC's syllabus be malleable to the needs of the students. RPGs are engaging, encouraging agency and ownership, and rely on communication to succeed - all factors that are vital to a student's development in the classroom.

In 2020, KQED ran an article entitled "Five Best Practices Teachers can Learn from Dungeon Masters." Several educators, whose classes ranged from middle school to college, were interviewed on how they incorporate tabletop games into their classes to improve student 
performance. Sarah Roman, a high school teacher, compared creating a syllabus to preparing a D\&D campaign: "you set aside time to craft a campaign (lessons), put in roadblocks and problems (individual lessons), craft puzzles and dungeons that scale in difficulty (tests), all while making sure to understand the people with whom you're working. In both cases, you become the leader and entryway to a world they've never experienced" (Darvasi). Furthermore, the article stresses that teachers and educators shouldn't be afraid to offer their students a level of freedom and choice in how their classes unfold; students can enjoy more meaningful learning environments when the lessons and assignments are accommodating to their needs. And this isn't specifically for educators seeking to use TTRPGs in the classroom as projects or activities, but advice on how teachers can be more comfortable with taking a step back in their curriculum. In continuing to challenge how the education system approaches pedagogy and composition, "the plasticity of RPG systems allows for the implementation of any theme or setting, and students can be recruited to help design the games around a specific topic" (Darvasi). The more invested a student is in the class's activities and subjects, emotionally and creatively, the better the experience will be.

I noticed in my ARP that the students who put the most time and effort into my RPG-like assignments had the higher grades at the end of the semester, as well as the most introspective self-reflection letters on how they grew as a student. That they had the freedom to tell the kind of story they wanted yet were able to come to me for help and advice on how to execute the story, told me that educators often underestimate their students' ability to engage with classroom materials. I changed my own approach to how I taught: instead of thinking of myself as a lecturer, speaking from pre-scripted lesson plans to disengaged students, I pretended I was the GM and my students were my players. Instead of lectures, I encouraged my students to share 
their thoughts and opinions on the readings and homework through discussion forums.

Sometimes, all I had to do was pose a single question to the class, then I could sit back and watch with a smile as they engaged with each other. It was far more fulfilling for me and them, to help me gauge their level of understanding of the content, and to rearrange lesson plans on the fly to best suit the narrative direction my class was taking. Rather than assuming my students would absorb information and moving forward without addressing it, I'd take the time to engage with the content to ensure no one was left wondering what the heck they'd read for homework the previous night. Even better, sometimes a student would bring in outside knowledge or a wild opinion that I'd never heard before but I could grasp and build on, just like I would take my players' ideas in my campaign and run with those threads instead of my own plan.

In comedy, the most vital part of keeping an improv session going is the ability to answer the question: “yes, and?" A tabletop game's most basic goal is to capitalize on that question to drive the narrative forward. A GM must be able to take a player's idea and incorporate it into the greater story, allowing their characters to make meaningful contributions to the world around them and take an active role in the preservation - or challenge - of the status quo. Similarly, an educator must be able to take a student's response to a lesson and incorporate their questions into the greater curriculum, allowing their students to gain meaningful knowledge and experience from having taken the class.

Educators looking to possibly incorporate TTRPGs and RPG-like assignments into their curriculum shouldn't feel despondent or overwhelmed on how to do so. Popular systems like D\&D might be complex and expensive, taking a lot of time to learn before a game can be played, but there are hundreds of games out there that accommodate almost any play style imaginable. Some games are specifically designed to be "rules lite," meaning they're easy to learn and easy 
to play, and even more are focused on short-term campaigns that can be completed in hours rather than years. Grant Howitt, a powerhouse in the TTRPG community, is the mastermind behind dozens of "one page games" like Honey Heist, where everyone plays as criminal bears; Adventure Skeletons, where everyone plays as skeletons just trying to have fun; and Crash Pandas, where everyone plays drag-racing raccoons all trying to drive the same car at the same time. While the premises are definitely comedic and geared towards lighthearted play, games like these can easily be used in classrooms due to the simplicity of the mechanics and the ease of access - one of Howitt's biggest draws is his pay what you want mentality for the shorter content. Rather than spending \$50 on the Player's Handbook for D\&D (not to mention the extra money for dice, the Dungeon Master's Guide, and all the other optional resources to run a game), a middle-school teacher on a budget can, for the same price or less, download a dozen of Howitt's games for their class to play.

The more unconventional the lesson plan, the more engaged a student will probably be with the novelty of the assignment. The more accommodating and approachable the game, the more enjoyable the story will be. And the more the players are encouraged to contribute, the more likely they'll be to pursue TTRPGs beyond the setting in which they started. There are dozens, hundreds, thousands of official and fan communities alike for the many, many games that exist; with advice, announcements, recommendations, original and custom content to spice up the core systems, TTRPGs are far more collaborative than meets the eye at first glance. 


\section{Communication and Community}

\subsection{Take A Chance, Roll The Dice}

Of course, collaborative storytelling mandates at least one other person. It can be daunting to work with other authors so closely, especially for students who haven't done anything like it before. Finding the right people to work with, whether for a school assignment or finding a game to play, in addition to knowing ahead of time what kind of story you want to tell are vital to success. While authors might have experience in inhabiting their characters, assuming their personas to write the stories, tabletop narrative structures hinge on becoming those characters in front of an audience. It can be intimidating even to veteran players, and of course acting doesn't come naturally to everyone; the idea of having to roleplay characters can run the risk of psyching out students if such an assignment is sprung on them with little notice or time to get to know their peers. When introducing tabletop narrative structures into pedagogy, it might be a good idea to give students a preview into the gaming community - which, thanks to the surge in popularity due to the increased ease of accessibility in recent years, is relatively easy to do. Even if, in the end, students don't quite find that collaborative storytelling or TTRPGs are quite their style, they might find an interest in the communities they've been introduced to.

The online RPG community is a bit of an umbrella - in reality there are dozens, if not hundreds, of smaller groups and conversations happening over a number of websites including Twitter, Reddit, custom Wikis, and Discord channels. Depending on which TTRPG educators might want to emulate or run, there are many resources to turn to for information on how to structure the collaborative aspect, like finding actual-play podcasts or Twitch streams to see 
mechanics and roleplaying in action, in addition to simply reading the manuals. The recent surge in popularity certainly sets a precedent that collaborative storytelling isn't a short-lived or fading fad. RPG creators are constantly publishing new content, both original games and third-party modules for existing IPs. According to a 2020 report published on Polygon.com, gaming projects like TTRPGs and board games make up roughly one-third of the revenue generated on Kickstarter going back at least five years, indicating a consistent and continued interest in the narrative structure these games provide. One such example was when the D\&D streaming show Critical Role launched their Kickstarter campaign to raise $\$ 750,000$ in 45 days to fund an animated movie based on their game - and thanks to their massive fanbase, the campaign raised over $\$ 1$ million within the first hour and ended with over $\$ 11.3$ million, making "the fundraiser the most successful film or television project in Kickstarter history. More than 88,000 people contributed to the campaign" (Whitten). Critical Role itself remains among one of the most popular TTRPG streaming shows with over 500 hours of gameplay available on Twitch and YouTube, and its fanbase is one of the most active in community forums. Students and educators wanting to see examples of gameplay can easily watch clips and segments to see how players can come together to create the story.

But even the closest of collaborators might not always agree on how things are going. Sometimes there are disagreements with interpretations of rules or how certain adventures are presented. Creating games takes collaboration and agreement, skills that can and should be fostered in education. As I wanted to explore with my composition class, TTRPG-like assignments encourage and enable students to learn how to work with their peers even when not in agreement. John Trimbur, whose work on collaborative learning has been cited in Bruffee's and vice versa, discussed the importance of both consensus and disagreement when employing 
collaborative learning in a pedagogical setting: "consensus represents the potentiality of social agency inherent in group life - the capacity for self-organization, cooperation, shared decisionmaking, and common action... it does not inhibit individuality, as it does for those who fear consensus will lead to conformity" (604). Though originally published in 1989, much of his research and observations remain accurate to collaboration today. Trimbur argues that collaborative learning helps students undergo the stressful and often scary process of moving out of their comfort zones to establish new connections and familiarities, being willing to expose themselves to concepts and theories they might not agree with in order to learn and grow as people in a deeply interconnected society. Knowing how to identify and navigate such complex social structures is vital and encouraging students to participate in certain communities based on their pedagogical studies should be more commonplace, as "social relationships between players are modified by every action taken in the game... navigating, manipulating, and transforming these relationships is one way that players achieve meaningful play in the social realm" (Salen and Zimmerman 454).

Educators don't have to be limited to specific curriculum, though, to teach TTRPGs and foster collaboration. After-school programs and activities like clubs and student organizations, which are overseen by teachers, are one such method. Local game stores that host tournaments and open-table game days often have specific age or skill groups that curious players can sign up for, and are more than happy to run introductory games for students who might have caught the gaming bug from an assignment. Nonprofit organizations like 826LA, which supports students from elementary to high school by hosting after-school programs that focus on creative and compositional writing skills, host RPG workshops to teach students how to both play in and run games so they can put what they learn into practice. When like-minded individuals come 
together, enduring friendships can form that won't be broken by distance and time. However, it's also vital that students be taught how to establish and maintain boundaries - especially when relationships with others in a community are primarily or exclusively online; "TRPGs are an inherently social medium, and have the potential to enable students to collaborate in new and unexplored ways" (Woods 149). Unexplored can mean difficult to gauge, but no matter the outcome it will be a learning experience.

One simple school assignment can expose students to a whole new world of potential. Even though my particular assignments were kept fairly insular to the class, I could see the immediate effects of just how well my students warmed to the exercises. They were more engaged with each other and the assignments than I'd seen for a fair amount of the semester and were actively pursuing more creative mediums in which to craft the narratives other than a written short story. Though none of my students informed me of any particular interest in pursuing TTRPGs specifically, as I'd generalized the rhetoric around how I'd constructed the assignments, they did report an increased enthusiasm and interest in continuing to pursue collaborative work both in a personal and academic setting.

Some, in their end-of-semester reflection letters, even expressed regrets that previous group work they'd been a part of in other classes hadn't had that level of creativity and interaction with their peers. These students went on to describe their hopes of seeing similar assignments or activities in future classes, especially once we were no longer remote learning. Several groups reported friendships that had sparked from simply exchanging contact information to work on these projects, showing the growth of community and connection in real time over the semester. I have no doubt that, had we been in the classroom together, the relationships established would have been even tighter. That they were so receptive to such a 
freeform style of composition was a welcome reward; despite there being no dice rolls, no sheets full of stats and abilities, no GM to run the narrative for them, the framework of an RPG emulated through the assignment prompts held strong between the collaborative efforts of the students to create a cohesive narrative. Arguably a much more creative endeavor than typical assignments in a composition course, it was nonetheless a successful method of evaluating student progress in understanding the intricacies of what makes a good piece of writing.

\subsection{Ruminations on RPG Narrative Structure}

Collaborative storytelling in TTRPGs is an ongoing conversation from the first session to the last. For every in-character lore drop and tantalizing cliffhanger the GM hands out to their players, there are out-of-character discussions and conversations discussing all aspects of the game. In my own experience, I found that much of the friction and annoyance that naturally occurred during gameplay stemmed from miscommunication or lack of full disclosure between me and my friends. When running my D\&D campaign, I am often loathe to drop into a metaconversation because I just enjoy living in the immersion the game creates; the issue with this, unfortunately, is that sometimes it restricts me and my players from having certain discussions about how to proceed forward when the information we need to talk about isn't something the characters themselves would know.

Recently, this very instance occurred during a very emotional and high-stakes story arc involving my players facing off against a horde of marauding orcs. Their adventuring party was outnumbered nearly twenty to one, the town they were trying to help defend was struggling to rebuff the daily raiding parties, and they knew little of how the horde's leadership operated which made planning to take out the leaders nearly impossible. I could see the frustration in my 
players' faces and heard them struggle to elaborate on their ideas for how to tackle such a threat while still limiting themselves to the little knowledge their characters had. It was a recurring issue in both this game and the City of Mist campaign I participate in with the same group of friends. The GM of that game elected to drop out of character quite often, allowing us players to go over the rules and mechanics of the game whenever we felt stuck during an investigation, using our knowledge of how to set up different kinds of sequential rolls to better boost our chances of success. Outside of our game days, we had group texts in which we'd send our ideas, predictions, and occasional complaints to each other so we'd all be on the same page and not grind the games to a halt with arguments or disagreements.

I will admit that, not being as seasoned a player or GM as some of my friends, I found it hard to let that happen with my own game. It took several conversations and offers of mediation for us to reach an understanding: it was okay to drop out of character to talk about what wasn't working and to voice our frustrations, even if it halted the session. I realized that, for all the research I'd done on how to run games, all the articles I'd been reading to prepare for teaching and assigning my RPG-like projects to my students, I had failed to take my own advice for communicating. I had to acknowledge that sometimes, relinquishing control over the immersion and narrative was better than muscling through it. For as much power as I wielded, being the DM, the success of the game and the story ultimately depended on my players.

In my CoM campaign, one of my friends voiced his frustrations at the end of one night's session as he felt his character was falling to the wayside in terms of personal growth and development. He was struggling with the system, unsure of how to play more into his stats and weaknesses to facilitate scenes. And then, he said the magic words: "can I ask your guys' opinions?" It opened up a wonderfully productive conversation for all of us as he voiced his 
hopes and intentions what he'd like to eventually see with his character, and we were able to offer our suggestions on how to best head in that direction. Asking for help can make us feel vulnerable, especially with something as personal and emotional as characters we've spent weeks, months, and even years playing. After all, even if each character in a campaign has their own personal story arcs to go through, the players are writing the stories together. It's difficult to break away from that isolated mindset of needing to keep things close to the chest; that "writing is misunderstood as a solitary activity, when in reality all writing and communication occur[s] in relation to other people, within the context of a culture, language, and many other preconditions" (Woods 149). Whether help comes in the form of reaching out to friends or crowdsourcing from the greater RPG community, communication and collaboration is occurring for everyone involved.

In reflection, similar conversations and sentiments were being navigated in my composition classes. Communication and understanding of expectations was key to being able to complete the assignments - though it was rare, there were a couple cases in which I was made aware that a student wasn't contributing to the assignments, forcing their group members to pick up the slacks and fill in the blanks left by the absent author. Part of this could have stemmed from us being remote and communication being limited to emails, texts, or Zoom messaging rather than in-person conversations. Part of it could have stemmed from an unconscious hesitation or fear to be pushed out of their comfort zones when asked to work on something so creative. In a way, each student was a co-GM of the exercise, struggling to find the balance between author and participant when combining their ideas into the narrative.

Yet, despite the shortcomings and struggles, the gaining of skills and improvements in composition were immediately noticeable. Even after the collaborative assignments concluded 
and the students went back to individual work for their final projects, all of them demonstrated a marked changed in their writing when compared to the beginning of the semester. Some enjoyed the experience so much that they elected to return to their groups to work together on the class's final project, displaying a continuing interest in collaborative work. Had I the resources and ability to create assignments even closer to a TTRPG, there is little doubt in my mind that they would've shown interest in continuing gaming beyond the classroom. In my current class this semester, in which I've planned to continue assigning these writing prompts, simply describing them ahead of time was enough to elicit excitement from my new students. It's become quite obvious to me that, given the opportunity, students will gladly explore collaborative composition.

In addition to communication, improvisation, problem solving, and other skills RPG systems teach, the break from traditional formatting is a welcome change to students and TTRPG veterans alike. TTRPGs and traditional narratives may have both started with pen and paper, but they've evolved far beyond such limitations. The explosion of actual-play games has proven audiences will flock to all kinds of storytelling like watching streamers on Twitch or YouTube; listening to pre-recorded podcasts or audiobooks; playing online simulators that recreate a tabletop game with the addition of digital assets to spice up the immersion; and using Zoom, Skype, or other video calls to host readings, panels, talk shows, or Q\&As to live audiences. And, of course, fans of particular mediums will seek each other out. New wiki sites will be created, Reddit forums will go live, fanfictions will be churned out, and social media will be set ablaze with each new installment of the narratives.

Educators can take inspiration from these endeavors when crafting curriculum. Let students work together on projects. Encourage them to engage with forums and chat rooms when 
researching projects. Give them assignments asking them to observe online communities and how they operate. Break up the monotony of academic assignments by throwing in a splash of creativity. The more unique and engaging the pedagogy, the more successful the class will be. Even the most skilled writer, whose experience may be almost entirely solo, will find their creativity and ingenuity challenged by the prospect of collaborative writing.

I, for one, know that I wouldn't be half as creative or enthusiastic about writing as I am had I not been exposed to the unconventional storytelling of TTRPGs. My experiences have had a marked influence on how I approach narratives, no matter if I'm drafting a future story arc for my campaign or outlining a novel for a personal project and have opened my mind to a whole new world of compositional possibilities. Had there been such opportunities to learn about gaming as narrative and composition when I had been a student, I know for sure that I would've thrown myself into collaborative work with all my effort. I've long been of the opinion that the best way for an author to write is to have a community to share their ideas with, to be able to ask for advice and input with how to proceed, and TTRPGs are the perfect way of learning how to balance control of the narrative with the impulsiveness of pursuing the ever-present question of "what if?"

And, most importantly, it's vital that all GMs remember that even the best laid plans can be derailed by the players' actions. In Appendix B, I describe one of the adventures I'd written up for my D\&D campaign - what I'd envisioned as a layered but ultimately straightforward mystery surrounding missing children and a cursed forest - and my expectations for how my players would solve it, only for them to take a completely different approach that I wasn't entirely prepared for. Even though the adventure itself was fun and the mystery ultimately solved, it took a lot of improvisation and split-second decision-making on my end to keep the 
narrative moving as I reacted to the direction the investigation ended up taking. It was certainly one of my most memorable experiences as a DM, and I learned a lot about resisting the temptation to continually redirect the players towards what I'd expected. The successes and failures in running a game pay themselves forward, giving everyone involved numerous chances to learn and grow throughout the adventure. I've learned from my friends and their experiences and have seen my students warm to the prospect of collaborative activities over the course of the classes. 


\section{Conclusion}

Tabletop roleplaying games, though unconventional in narrative structure, are an untapped well of teachable skills and creativity. Participating in TTRPGs is a continual learning experience for everyone involved, player and GM alike. Even the most seasoned of GMs can still be blindsided by player choices and sudden story direction, having to turn on a dime to accommodate the latest of failed dice rolls or impulsive character actions. Systems and settings are constantly being revised, updated, and overhauled to accommodate the constant feedback from fans and enthusiasts, keeping content fresh. Rich communities foster mutual creativity, spark long-lasting relationships, and offer countless ways for curious newcomers to find what fits their style best. Incorporating TTRPGs into pedagogy might be intimidating to educators not familiar with the narrative structure, but modern RPGs have been increasingly and intentionally designed with a low barrier of entry to accommodate the influx of players over the past couple decades. Using RPG-inspired assignments, or even running actual TTRPGs for students, is more than simply making a fun collaborative project.

Collaborative storytelling itself is hardly novel; however, tradition has long mandated that storytelling be individual by nature, painting that idyllic mental image of an author holed up alone in a room day after day until they emerge with a finished narrative. The act of creating a story that's collaborative from the very onset is what's innovative. An author might have a team of editors and beta readers to help them shape the final draft of their novel, but the vast majority of that novel was written by that single author and thus will remain mostly unchanged even after feedback. TTRPGs, on the other hand, are built upon a group of authors constantly in 
conversation with each other from the beginning, helping each other to shape the story from the moment the characters are created to the moment the GM says, "the end." The collaborators are fully immersed in the development of their characters, emotionally invested in seeing the best possible story they can tell through the luck of the dice and the whims of their decisions. They get to be active participants in a world that they helped shape, learning how to roll with the punches when plans fall apart and to improvise when all else seems to fail. Gaming teaches communication, problem-solving, acting, even diplomacy. Being able to think on your feet is a valuable skill, made all the more important to have when your GM starts a timer and tells you the encroaching walls of spikes surrounding your adventuring party will squish you when it hits zero, and you have to find the hidden mechanism to stop the trap in real time. Learning to deal with the consequences of your actions is vital to navigating academic and professional careers, as you can neither take back that nasty email to your supervisor, nor can you "un-kill" that city guard who sassed your bard for their failed persuasion roll.

Composition is no more limited to single-author projects than media is limited to paper books. Even if educators don't realize it, students are much more receptive to collaborative projects than they might expect. Working in groups falls short only when they're feeling unfulfilled in creativity and expectations. Creating writing assignments in the vein of TTRPGs helps to free the minds and assumptions of student and teacher alike from the narrow structure of linear narratives, opening up a world of exploration and innovation in approaching craft. Unconventional only because higher education shies away from such "unacademic" endeavors, using gaming as pedagogy has a much higher appeal to newer generations of tech-savvy students than assigning yet another PDF of a badly-scanned article for them to read and take notes on. 
Learning is best with a hands-on, immersive approach in the subject matter, so it's okay to loosen the reins and let students take the initiative on how they best complete the project. TTRPGs, like classrooms, are an agreement between the author in charge and the audience shaping the outcome. By facilitating conversation, games allow for participants to share their opinions and ideas on how best to proceed while simultaneously acknowledging each other's individual expectations and desires. The journey from start to finish is constantly evolving to accommodate everyone, crafting a truly unique and innovative storytelling experience unlike anything else in media. 


\section{Works Cited}

Aarseth, Espen. "A Narrative Theory of Games." International Conference on the Foundations of Digital Games. Raleigh: Association for Computing Machinery, 2012. 129-133.

Abbott, Benjamin. "How Do You Write a Dungeons and Dragons Campaign?" 12 March 2021. GamesRadar. https://www.gamesradar.com/how-do-you-write-a-dungeons-and-dragonscampaign/?utm_content=gamesradar\&utm_campaign=socialflow\&utm_source=twitter.c om\&utm_medium=social.

Bogost, Ian. "The Rhetoric of Video Games." The Ecology of Games: Connecting Youth, Games, and Learning (2008): 117-140.

Bruffee, Kenneth. Collaborative Learning: Higher Education, Interdependence, and the Authority of Knowledge. Johns Hopkins University Press, 1999.

Calleja, Gordon. In-Game: From Immersion to Incorporation. Cambridge: The MIT Press, 2011.

Cover, Jennifer Grouling. The Creation of Narrative in Tabletop Roleplaying Games. North Carolina: McFarland \& Company, Inc., 2010.

Darvasi, Paul. "Five Best Practices Teachers can Learn from Dungeon Masters." 6 February 2020. KQED. https://www.kqed.org/mindshift/53553/five-best-practices-teachers-canlearn-from-dungeonmasters?utm_campaign=npr\&utm_medium $=$ social\&utm_source=twitter.com\&utm_term =nprnews.

Dominguez, Ignacio, et al. "The Mimesis Effect: The Effect of Roles on Player Choice in Interactive Narrative Roleplaying Games." CHI Conference on Human Factors in Computing Systems. New York: Association for Computing Machinery, 2016. 34383449.

Goetz, Christopher. "Trellis and Vine: Weaving Function and Fiction in Videogame Play." Gaming and the Arts of Storytelling (2018): 29-43.

Kennedy, Krista and Rebecca Moore Howard. "Collaborative Writing, Print to Digital." A Guide to Composition Pedagogies. New York: Oxford University Press, 2013. 37-54.

Mawhorter, Peter et al. "Choice Poetics By Example." Gaming and the Arts of Storytelling (2018): 57-72. 
Mawhorter, Peter et al. "Towards A Theory of Choice Poetics." University of California, Santa Cruz, 2014.

Salen, Katie and Eric Zimmerman. Rules of Play: Game Design Fundamentals . Cambridge: The MIT Press, 2004.

Trimbur, John. "Consensus and Difference in Collaborative Learning." College English, Vol. 51, No. 6 (1989): 602-616.

Trivedy, Kiran. "Vampire: The Masquerade Shows the Right Way to Confront an RPG's Problematic Past." 28 January 2021. Dicebreaker. Dicebreaker. $<$ https://www.dicebreaker.com/games/vampire-the-masquerade-v5/opinion/vtm-confrontproblematic-past-dnd>.

Whitten, Sarah. "'Dungeons and Dragons' Kickstarter Breaks Record with \$11.3 Million Campaign." April 2019. CNBC News. https://www.cnbc.com/2019/04/19/critical-rolevox-machina-kickstarter-ends-with-11-million-in-funding.html.

Woods, Timothy. Anything Can Be Attempted: Tabletop Roleplaying Games as Learning and Pedagogy. PhD Thesis. New York: St. John's University, 2017. 


\section{Appendix A. Sample FYC Assignments}

\section{A.1 Prompts Given in English 103 FYC Course}

\section{Homework Exercise: Monster Hunters}

This was a two-part writing exercise split up between two assignments - one for preparation, and one for execution. Students were allowed to choose their own groups for this assignment instead of being placed into groups by the professor. Part of allowing students to choose their groups was to allow those who had already worked together well on previous assignments to continue working with others they knew they would get along with.

The Assignment: This will be a collaborative, creative assignment. In conjunction with Exercise 8, which will also be collaborative, you will be forming a paranormal investigative squad with your group members. Exercise 7 is a character-building activity, in which you will create an investigator that you will "play" for Exercise 8. When coming up with the different aspects and personalities of your characters, think back to the different articles we've read about why people believe/disbelieve in the paranormal, what would motivate them to investigate, and what they hope to get out of it.

You will meet in your groups during class time to create your character. There will be some established backstory that you will all decide on together: you're a group of paranormal investigators, monster hunters, alien enthusiasts, etc. Each of your characters will have some experience or belief that has brought them all together. In your group, decide on the backstory of your mystery gang:

- How long have you all been working together?

- How did you all first meet? What has kept your group together this long?

Then, you will start developing your character's individual backstory. Flesh them out: give them a personality, a job (are they currently employed, or did they quit to pursue this paranormal investigative job?), family/friend relationships, etc. Then, elaborate on questions like these:

- Are they a skeptic or a believer? They must've had some kind of paranormal experience in their past that spurred them to seek out their fellow investigators - an alien abduction, 
a poltergeist, demonic possession, or something else. Did it happen to them, or a friend or family member?

- If they're a believer, what kind of proof are they looking for? If they're a skeptic, are they hoping to find evidence that discredits the paranormal, or are they in denial about their experience and think that finding evidence that confirms the paranormal will change their mind?

- What drives them? What's their yearning? It can be money, fame, curiosity, fear, etc.

- What are their relationships to their fellow investigators? Do they like any? Are they suspicious, paranoid, or annoyed by any? Do they think another is faking?

- What is their role in the group? Are they the tech master, the damsel in distress, the driver, the historian, the psychic, the tough guy, etc? How are they integral into the group - if they were not present, what would the group be lacking?

In your groups, discuss these characters as they start to coalesce. Figure out the dynamics, the relationships, the problems and the benefits.

When you've got a fairly good idea for who you want this character to be, start writing it down. You can structure this like a biography of their life, bullet points describing them, breaking it into sections, or some other format. Include all the details you can, to help you and your groups create a cohesive cast in preparation for solving a mystery in Exercise 8.

\section{Homework Exercise: Mystery Gang}

This is part two of the Monster Hunters assignment. After the students in each group had met to discuss who their monster hunters were, how they knew each other, and why they worked together, this assignment now asked the students to craft a mystery for their hunters to solve. The format was left open to the students: it could be a written story, vlogs, a podcast, diary entries, or any other creative medium they wanted to explore.

The Assignment: This will be a collaborative, creative assignment. In the same groups you worked with for Exercise 7, you will come together with your characters to take a paranormal mystery from a job board to solve. You can come up with your own scenario, or use a scenario similar to these examples:

- Ghost hunters - you are doing a one-night lockdown in a supposedly haunted house 
- Cryptid Seekers - you're investigating a local legend, interviewing locals in a small town and searching the area for signs of your quarry

- Alien Enthusiasts - everyone knows the government is covering up the alien ship that crashed in Roswell, New Mexico. Abductions are real. Crop circles are signs they are coming. And the mysterious lights that appear overhead at night are obviously signs they're already here. How do you prove it?

- Another similarly themed mystery of your choosing. If you have questions or concerns, please run your idea past me.

As part of this assignment, you will include a summary of the mystery you decided to investigate. Decide on the following aspects:

1. The mystery - what are you investigating? Describe the setting and what drew your group to it. 2. The nature of the investigation - what are your intents? Are you capturing the cryptid or just trying to get evidence like photos/videos, footprints, hair samples? Are you exorcising a ghost/demon? Are you trying to prove the location isn't actually haunted? Are you hoping to convince the townspeople aliens don't actually live among them?

3. Complications - something is standing in your way. Is it one of you? Is one of you secretly a government agent who infiltrated this group to ensure any evidence recovered never makes it to the media? Or is one of you possessed part way through the investigation by the ghost/demon? Is one of you an alien in disguise, or a shapeshifting monster hoping to pick the rest off one by one? Or is it an external factor - you're racing against government agents to free a wrongly-captured cryptid, is the cursed necklace being shipped to an auction the next morning, or will another child from town be abducted from their beds and never seen again?

4. Resolution - were you successful? Did you solve the mystery? Or did your quarry elude your grasp once again? Did all of you make it out alive and/or unscathed? What evidence did you recover, and what do you plan on doing with it? Did any secrets from your fellow monster hunters come to light that brought you closer or tore you apart? Was this investigation real, or was it yet another man in a mask or an old creaky building?

Work together and document your investigation to solve the mystery - record yourselves acting it out in a video call session, keep a log of your character's personal notes (like a diary or speaking into a recorder) as the mystery progresses, take notes and write a testimony in the aftermath - get creative! I highly encourage you to work out ways of communicating or meeting 
up outside of class to work on this. Google Meets or Skype are great, free video call programs if you want to meet face-to-face, or utilize group chats like text, Facebook, Instagram, etc.

\section{A.2 Overall success of the assignment}

Expectations actually matched reality, in this case. Though the quality of the assignments varied slightly between groups, overall it was incredibly successful. The students demonstrated an enthusiasm and creativity that, until that point in the semester, had somewhat been lacking with other individual writing assignments. The collaborative nature of the assignments allowed them to discuss several different kinds of approaches they could take to the formulation and execution of the narrative, while also necessitating constant communication between them so their stories were cohesive when put together.

\section{A.3 Student Feedback/Reactions}

When I asked what they'd thought of the assignments, I was inundated with positive responses despite some of the communication hurdles groups experienced throughout the work. Three of the groups ended up asking if they could continue building on their assignments, and working with each other again, for the final project of the course. Overall, students cited the unconventional brainstorming and writing demands of the prompts as spurring them into previously uncharted territory for them, while simultaneously allowing students from nonwriting majors to flex their skills in organization, planning, and composition. 


\section{Appendix B. Adventure Expectations vs Reality}

\section{B.1 Adventure Overview For Homebrew D\&D 5E Campaign}

This adventure was originally written and designed for a $5-7^{\text {th }}$ level D\&D adventuring party, taking place in my original campaign setting. The party consisted of five players/characters: a half-orc paladin, a dwarf cleric, a half-elf bard, a tiefling monk, and a halfelf warlock. I structured this adventure to play on both the party's strengths and weaknesses, hoping to have my players rely on their investigation skills while seeing if they could resist the temptation to pursue dangerous curiosities.

The adventure took place in a small town called Elthys, which sat on the edge of the massive Wenn Grove forest. Numerous rumors and urban legends were whispered about the forest, though in recent decades the stories turned sinister to reflect the slowly encroaching corruption that twisted the trees and the denizens within. Traders and travelers who had once crossed the roads without fear now preferred to circumvent the forest, and the inhabitants of Elthys started noticing that young children from their town were disappearing with increasing frequency. Tales of a trickster spirit that played pranks on the unsuspecting started to be interwoven with a strange fog that would fill the town's streets at night - a precursor to a disappearance. Growing desperate, the townsfolk began advertising rewards for any adventurers who could potentially find whoever, or whatever, was spiriting their children away... for none were ever seen again. 


\section{B.1.1 Initial Expectations}

I'd planned a number of possible routes my party could pursue in their investigation, including a whole cast of NPCs they could talk to and evidence they could find. Several notable locations were mapped out, including the Mayor's Office, several grieving parents' homes, the Hunter's Lodge, and the Wenn Grove itself. Within these locations, they could speak with the Mayor or his assistants, the parents or other children, the only hunter still brave enough to venture into the forest after dark, and the playful faerie dragon who lived in the trees.

The party could find evidence pointing to the true culprit and how the corruption came to be: a terrible, insidious hag who disguised herself as an innocent elderly woman living in town. Her true home, however, was a decaying cabin that appeared after dark, cloying mist pouring from the broken windows and door to fog the minds of the townspeople while she played a hypnotic tune on a magical pipe to pull a child from their bed. Evidence came in the form of both objects and information: the faerie dragon could tell the party that the strange music came from a pipe once belonging to the protector of the forest, a dryad who lived in a now-sundered tree and whose "heart" was stolen by the hag to strengthen her magic. The children who disappeared left behind rusted iron nails, given to them by the hag so she could speak to them in their sleep and draw them from their homes in a trance. During the day, the party could also come across children playing in the town square and singing what sounds like a nursery rhyme at first but contains a warning in the words.

I expected the party to spend their initial investigation in the town, using the diplomatic and persuasive skills of the bard and the warlock to convince the weary townsfolk to talk to them, before paying the hunter to take them into the woods. Once in the forest, I'd planned for them to be pranked by the faerie dragon while they slept, and to hunt down the playful 
perpetrator in response. If they were cordial, the dragon would tell them of the forest's history and the decay stemming from the dying dryad's tree - and if they asked about the disappearing children, the dragon would tell them of a strange cabin that appeared at night, belching mist and from which a massive, hunched creature would emerge to play music. If they returned to town, they could have a chance encounter with an innocent old lady, but the more insightful characters could see she was hiding more than she knew. If they decided to stake out the town at night, they'd hear the music and see the fog fill the streets, and could follow a hypnotized child into the forest to see where they'd be led. From there, they could try to save the child before entering the cabin, only for the hag to appear and fight them, or they could follow the child into the cabin and fight the hag in her home turf: a special pocket dimension of dead trees and thick fog.

\section{B.2 How It Actually Went}

My players, being stubborn and cautious, refused to venture far into the forest despite the hints the faerie dragon was dropping about needing to heal the corrupted tree in the center of the Grove. Feeling more confident when surrounded by civilization, they elected to try and lure the culprit of the disappearances into the center of town to launch an ambush. With the forced change in terrain, I needed to quickly adapt how the hag would react to the adventurers who decided to patrol the streets every night in search of entranced children. Breaking my own "rules" for how and when the cabin appeared, I decided to have it manifest in the center of town and the hag would call almost all the children at once to distract the party, in hopes of being able to lure at least a couple into the cabin's pocket dimension before disappearing again. This was partially successful, though my (and the hag's) plan was nearly foiled by the paladin attempting to block the door from closing. 
Noticing the players was getting frustrated with the relative lack of leads, since they hadn't spoken to as many townsfolk as I'd expected, I decided to have one of the mourning parents of the recently stolen children attract the party's attention with her loud sobbing. The monk, being an empathetic character, took the bait and finally asked if she could search the child's bedroom for clues. This finally allowed me to show them the iron nail, which in turn allowed the cleric to cast a spell to track the source of the nail's enchantment to the old lady's home. In the old lady's home, they found more nails and - in my desperate improvisation to give them a solid lead - an iron key that, when inserted into a keyhole, opened the door into the pocket plane. It was only after gaining this key that they leapt into the pocket dimension to face the hag and save the children.

Once that was done, I'd also expected them to retrieve the magical pipe and either keep it, as it was a powerful item they could use, or take it to the center of the forest to "return the heart" and heal the corruption. They elected to do neither, instead persuading the faerie dragon to take the heart while they continued on their journey to their original destination. A lot of the interactions, dialogue, and clues I'd planned out ended up never coming to fruition, and the progress of the investigation ended up a lot more convoluted than I'd expected. Though the mystery was ultimately solved, the hag killed, the children rescued, and the forest healed, the players' caution and hesitation to engage with the threat until forced to when they ran out of leads made me rethink my entire approach to writing out adventures for future story arcs. I'd have to be a lot more open-ended with the clues and possibilities, and not expect them to pursue things in any particular order. 